$\begin{array}{lccc} & \begin{array}{c}\text { Weight. } \\ \text { kilos. }\end{array} & \begin{array}{c}\text { Height. } \\ \text { cm. }\end{array} & \begin{array}{c}\text { Strength. } \\ \text { kilos. }\end{array} \\ \text { Prepubescent. } & 36.7 & \text { I49.8 } & 32.5 \\ \text { Pubescent. } & 41.8 & \text { I53.I } & 30.4 \\ \text { Postpubescent. } & 49.3 & \text { I62.6 } & 42.9\end{array}$

The differences in weight, height and strength between prepubescents and postpubescents of the same age are equal to the differences between age groups that are 6 to 8 years apart.

Conclusion. - Age groups are heterogeneous and cannot serve as a unit for reference and experiment. We must substitute groups based upon physiological age.

$$
\text { I6 (272) }
$$

\title{
Gastric peristalsis after section of the vagi and splanchnic nerves.
}

\section{BY JOHN AUER.}

\section{[From the Department of Physiology and Pharmacology of the Rockefeller Institute for Medical Research.]}

Some time ago I described a method by means of which gastric peristalsis in the rabbit could be studied under normal conditions, without any operative interference whatsoever. The method is briefly as follows : If the hair of the epigastrium of a rabbit, fed well two hours before, is cut short, the stomach is largely outlined through the abdominal wall, and the peristaltic waves may be studied by inspection or by registering the waves with a tambour.

As the stomach is provided with extrinsic nerves (vagi and splanchnic) and with an intrinsic system (plexuses of Meissner and Auerbach) it was of interest to study the mobility of the stomach when deprived partly or entirely of its extrinsic innervation. This question has been studied by a number of observers, most recently and thoroughly by Cannon who used the $\mathrm{X}$-ray method on cats. By means of the simple and physiological method outlined above the effects of sectioning the vagi or the splanchnics or both were studied. The vagi were, in this series, invariably cut below the diaphragm in order to preserve the vagus innervation of the thoracic viscera.

First series. Subdiaphragmatic section of the vagi only.-Two 
hours after operation the tambour registered only very slight volume changes of the stomach. Inspection showed no visible peristalsis. After some days peristalsis was again normal.

Reflex stoppage of peristalsis resulted from strong odors, sudden movements before the animal's eyes, loud noises, pain, just as in normal animals.

Second Series. Section of the splanchnic nerves only.-As a rule good, effective peristalsis occurred less than one hour after the operation. The waves, however, are slower, and the period of contraction seems to be of longer deviation than normally.

Regarding the reflex effect of sensory stimuli, the data are as yet too few to permit a definite statement, but it seems as if the ordinary stimuli employed exerted no marked effect on the course of stomach peristalsis.

Third Series. Section of vagi and splanchnics.-After section of all the extrinsic nerves peristalsis usually appeared within one hour but was not normal until some days after the operation.

The various sensory stimuli, which in the normal animal caused inhibition of the stomach movement, were now ineffective. The stomach, however, showed periods of inactivity alternating with periods of strong peristalsis. As these stoppages bore no definite relation in time to any stimulus applied to the animal, they were probably due to inhibitory influences exercised by the plexuses of Meissner and Auerbach.

These results confirm the statement that of the extrinsic nerves the vagi are chiefly motor and the splanchnics chiefly inhibitory for the motility of the stomach.

They also show that apparently normal stomach peristalsis is by no means dependent upon the extrinsic nerves, that the local mechanism is amply sufficient after some time.

The results show that the local nervous mechanism in the walls of the stomach must depend largely under normal conditions upon the directing influences of the vagi and splanchnics, for it usually takes days before the local government is able to produce strong, powerful, well-coordinated gastric waves. 